\title{
Comparison of Clinical Performance of the I-Gel with Laryngeal Mask Airway (LMA) Classic-A Randomized Study
}

\author{
Authors \\ G.Srinivas Rao ${ }^{1}$, Shivani.V ${ }^{2}$, R. Pandu Naik ${ }^{3 *}$, Mahender Kanuri ${ }^{4}$ \\ Assistant Professor ${ }^{1,2}$, Associate Professor ${ }^{3}$,Post graduate ${ }^{4}$ \\ Department of Anesthesiology, Osmania Medical College, Hyderabad \\ *Corresponding Author \\ Dr R Pandu Naik
}

Associate professor, Department of Anesthesiology, Osmania Medical College, Hyderabad,

Email: ramavathpandu9@gmail.com

\begin{abstract}
:
Background: Maintenance of airway is an integral part of general anaesthesia. Various airway devices are used for this purpose. Hemodynamic changes are major hazards of general endotracheal anesthesia and are probably generated by direct laryngoscopy and endotracheal intubation.

Aim: present study was undertaken to compare the performance of two supraglottic airway devices classic laryngeal mask airway and i-gel in anaesthetized, paralyzed adult patients posted for elective surgeries under general anaesthesia.

Methodology: One hundred patients, scheduled for various elective surgical procedures under general anaesthesia belonging to ASA class I and II were included in the study and were randomly divided into two groups with 50 patients in each group. In Group I $(n=50)$, $i$-gel supraglottic airway device was used and in Group L $(n=50)$ classic laryngeal mask airway (c-LMA)was used. Both the devices were compared in relation to the ease of insertion, number of insertion attempts, time of insertion, airway leak pressure, haemodynamic changes, intra and post operative complications.

Results: There was no statistically significant difference between the devices with respect to ease of insertion and number of attempts of insertion. The mean airway leak pressure with i-gel was significantly higher as compared with c-LMA $\left(26.14 \pm 2.57\right.$ and19.76 $\pm 2.04 \mathrm{~cm} \mathrm{H}_{2} \mathrm{O}$, respectively, $p=0.0001)$. The mean time of insertion for $i$-gel was $17.26 \pm 2.9$ secs which was significantly shorter compared to c-LMA with a mean insertion time of $24.9 \pm 4.8 \operatorname{secs}(p=0.0001)$. There were no statistically significant differences in haemodynamic changes and the postoperative complications between the devices.
\end{abstract}

Conclusion: Both i-gel and c-LMA are easy to insert and provide an effective airway during positive pressure ventilation, with $i$-gel providing a better airway sealing pressure as compared to c-LMA.

Key words: Supraglottic airway device, Laryngeal mask airway, Haemodynamic changes. 


\section{INTRODUCTION}

The supraglottic airway device is a novel device that fills the gap in airway management between tracheal intubation and use of face mask. Dr Archie Brain, a British anaesthesiologist, for the first time introduced the laryngeal mask airway in 1983, designed to be positioned around the laryngeal inlet that could overcome the complications associated with endotracheal intubation, and yet, be simple and atraumatic to insert. ${ }^{1}$ Careful observations and clinical experience have led to several refinements of Brain's original prototype leading to development of newer supraglottic airway devices with better features for airway maintenance. ${ }^{1}$ The wide variety of airway devices available today may broadly be classified as intraglottic and extraglottic airway devices, which are employed to protect the airway in both elective as well as emergency situations. ${ }^{2}$ As the time goes on, additional devices were added to the LMA family to satisfy specific needs, and a number of other devices were developed. There are a large number of supraglottic airway devices, some of which appear similar to the LMA family and others that work under a different concept. $^{3}$ Supraglottic airway devices are now widely used for surgery requiring general anaesthesia, so as to avoid the complications associated with tracheal intubation. ${ }^{4}$ LMA-classic is the gold standard for supraglottic airway devices and is in use since $1981 .^{5}$ The popularity of the device for routine use stems from its perceived benefits to the patient and anaesthetist over traditional forms of airway management. ${ }^{6}$ Laryngeal mask airway is a supraglottic airway device with an inflatable cuff forming a low pressure seal around the laryngeal inlet and permitting ventilation. ${ }^{1}$ The $\mathrm{i}$-gel is a new supraglottic airway device with a non inflatable cuff, composed of soft gel like, transparent thermoplastic elastomer. It is designed to achieve a mirror impression of pharyngeal and laryngeal structures and to provide a perilaryngeal seal without cuff inflation. A drain tube is placed lateral to the airway tube, which allows insertion of gastric tube. ${ }^{4}$ The primary limitation of the laryngeal mask airway (LMA) is that it does not reliably protect the lungs from regurgitated stomach contents, although it may act as a barrier at the level of the upper oesophageal sphincter if it is correctly positioned. The incidence of aspiration with the LMA has been estimated at $0.02 \%$, which is similar to tracheal intubation in elective patients. ${ }^{7}$ The newer supraglottic airway device, igel was introduced by $\mathrm{Dr}$ Muhammed Aslam Nasir in 2007. It has the potential advantages including easier insertion, minimal risk of tissue compression, stability after insertion and an inbuilt bite block. ${ }^{8}$ It seals the laryngo-pharyngeal space without any air being insufflated and additionally has an oesophageal lumen. It can be assumed that airway devices that offer an especially good seal and that are equipped with an additional oesophageal lumen are superior for use in patients with an increased risk of aspiration. ${ }^{8}$

\section{METHODOLOGY}

A study was undertaken in Osmania general hospital attached to Osmania Medical College during the period august 2013 to april 2016. The study was undertaken after obtaining ethical committee clearance as well as informed consent from all patients.

One hundred patients, scheduled for various elective surgical procedures under general anaesthesia belonging to ASA class I and II were included in the study.

\section{Inclusion criteria for the study}

- Adult patients aged between 18 and 50 years of both sex

- Mallampati grade I and II

- Elective surgeries under general anaesthesia with controlled ventilation

- Duration of surgery less than 60 minutes

\section{Exclusion criteria for the study}

- $\quad$ Age $<18$ years and $>50$ years

- ASA class III and above

- Mallampati grade III and above

- Emergency surgeries

- Head and neck surgeries 
Patients with decreased mouth opening ,increased risk of aspiration, abnormal or distorted anatomy of the pharynx, obstruction of the airway beyond the larynx, decreased compliance of the lungs and Obese patients with BMI $>28 \mathrm{~kg} / \mathrm{m}^{2}$

The study population was randomly divided into two groups with 50 patients in each group using sealed envelopes containing the name of the group and the patient was asked to pick up the envelope. The envelope was opened by senior anaesthesiologist who was not involved with the study.

Group I - i-gel group $(\mathbf{n}=50)$ and Group $\mathbf{L}$ classic LMA group $(n=50)$

Pre-anaesthetic evaluation was done on the evening before surgery. A routine pre-anaesthetic examination was conducted assessing: General condition of the patient, Airway assessment by Mallampatti grading and rule of 1- 2- 3 ,Nutritional status and body weight of the patient,

A detailed examination of the Cardiovascular system and A detailed examination of the Respiratory system. Haemoglobin estimation ,Urine examination for albumin, sugar and microscopy ,Standard 12-lead electrocardiogram ,X-ray chest/Screening of chest ,Blood sugar ,Blood urea, Serum creatinine were also investigated.

All patients included in the study were premedicated with tablet alprazolam $0.5 \mathrm{mg}$ and tablet ranitidine $150 \mathrm{mg}$ orally at bed time the previous night before surgery. They were kept nil orally for solids $10 \mathrm{pm}$ onwards on the previous night and for clear fluids upto 2 hours before induction. On arrival of the patient in the operating room, an 18-gauge intravenous cannula was inserted under local anaesthetic infiltration and an infusion of normal saline was started. The patient's head was placed on a soft pillow of 10 $\mathrm{cms}$ before induction of anaesthesia with the neck flexed and head extended. The patient was connected to multiparameter monitor, which records heart rate, non-invasive measurements of
SBP, DBP, MAP, etCO ${ }_{2}$ and continuous ECG monitoring and oxygen saturation. The baseline systolic, diastolic blood pressure, mean arterial pressure and heart rate were recorded.

The i-gel supraglottic airway was used in Group I patients. The size of the device was decided by anaesthetist based on patient's body weight and manufacturer's recommendation. Size 3 for patients weighing between $30-50 \mathrm{kgs}$, size 4 between 50-90 $\mathrm{kgs}$ and size 5 for patients weighing > than $90 \mathrm{kgs}$. Classic LMA device was used in group L patients. The size 3 classic-LMA for patients weighing 30-50 kgs, size 4 for 50-70 $\mathrm{kgs}$ and size 5 for patients of $>70 \mathrm{kgs}$. The standard pre use tests for both devices were performed. Both devices were lubricated using Lignocaine jelly on the tip and posterior surface as recommended by the manufacturer and the cLMA fully deflated prior to insertion.After recording the baseline reading, the patient was premedicated with injection Midazolam 0.02 $\mathrm{mg} / \mathrm{kg}$ body weight. Then the patient was preoxygenated with $100 \%$ oxygen for 3 minutes via a face mask with Bain's circuit. Intravenous lignocaine (2\%) $2 \mathrm{ml}$ was given to prevent pain on injection of propofol. Anaesthesia was induced with propofol $2.5 \mathrm{mg} / \mathrm{kg}$ body weight. Induction of anaesthesia was confirmed by loss of verbal communication with the patient and loss of eyelash reflex. Once an adequate depth of anaesthesia was achieved, patient was paralyzed by giving intravenous Succinylcholine $(1.5 \mathrm{mg} / \mathrm{kg}$ body weight). The patient was mask ventilated with $100 \%$ oxygen for 1 minute. The allotted device was inserted according to the manufacturer's instructions. The patient's head was placed in 'sniffing the morning air' position. The lubricated i-gel was grasped along the integral bite block and introduced into the mouth in the direction towards the hard palate and glided downwards and backwards along the hard palate until definite resistance was felt. The device was connected to breathing circuit and patient ventilated manually. The lubricated c-LMA was introduced in the classic method introduced by Dr. 
Archie Brain and the recommended volume of air was introduced into the cuff. ( $20 \mathrm{ml}, 30 \mathrm{ml}, 40 \mathrm{ml}$ of air for size 3, 4, 5 size LMA respectively). An effective airway was confirmed by bilateral symmetrical chest movement, square waveform on capnograph, normal end tidal $\mathrm{CO}_{2}$ and stable $\mathrm{SpO}_{2}(>95 \%)$. The device was secured with adhesive tape. Bite block was kept in case of cLMA and secured along with it with adhesive tape. Anaesthesia was maintained using 66\% nitrous oxide and $33 \%$ of oxygen with $1 \%$ sevoflurane. After the patient recovered from succinylcholine further neuromuscular blockade was maintained with vecuronium $0.1 \mathrm{mg} / \mathrm{kg}$ body weight. At the end of the procedure, patient was reversed with neostigmine $0.05 \mathrm{mg} / \mathrm{kg}$ body weight and glycopyrrolate $0.04 \mathrm{mg} / \mathrm{kg}$ body weight. The patient remained in the supine position and the device removed after the patient was fully awake and met all the reliable signs of recovery from neuromuscular blockade. The patient was inspected for any injury of the lips, teeth or tongue and the device for blood stain. 1824 hours after surgery, patient was interviewed for any post operative complications like sore throat, dysphagia and hoarseness.

Parameters studied during the procedure ease of insertion (Graded subjectively on a scale from 1 to 3), time of insertion, number of insertion attempts, airway leak pressure, Haemodynamic Parameters' Injuries, Post Operative Complications

The above haemodynamic parameters were monitored in the following time interval at Basal before premedication, At the time of insertion, 1 minute after insertion, 3 minutes after insertion, 5 minutes after insertion, At the time of removal, 1 minute after removal.

RESULTS Table-1: Demographic details

\begin{tabular}{|c|c|c|c|c|}
\hline \multirow{2}{*}{ Age (years) } & \multicolumn{2}{|l|}{ Group I(i-gel) } & \multicolumn{2}{|c|}{ Group L(c-LMA) } \\
\hline & No. of patients & $\%$ & No. of patients & $\%$ \\
\hline$<20$ & 2 & 4 & 1 & 2 \\
\hline $20-30$ & 17 & 34 & 17 & 34 \\
\hline $31-40$ & 20 & 40 & 21 & 42 \\
\hline $41-50$ & 11 & 22 & 11 & 22 \\
\hline Total & \multicolumn{2}{|l|}{50} & \multicolumn{2}{|l|}{50} \\
\hline Mean Age years \pm SD & \multicolumn{2}{|l|}{$34.0 \pm 8.68$} & \multicolumn{2}{|l|}{$34.0 \pm 8.27$} \\
\hline T value & \multicolumn{4}{|l|}{0.00} \\
\hline Pvalue & \multicolumn{4}{|l|}{$1.00(\mathrm{NS})$} \\
\hline \multicolumn{5}{|l|}{ Sex Distribution } \\
\hline Male & 26 & 52 & 25 & 50 \\
\hline Female & 24 & 48 & 25 & 50 \\
\hline Total & 50 & 100 & 50 & 100 \\
\hline \multicolumn{5}{|l|}{ Body Weight (Kg) } \\
\hline $40-49$ & 6 & 12 & 9 & 18 \\
\hline $50-59$ & 21 & 42 & 20 & 40 \\
\hline $60-69$ & 18 & 36 & 16 & 32 \\
\hline $70-79$ & 5 & 10 & 5 & 10 \\
\hline Total & 50 & 100 & 50 & 100 \\
\hline $\begin{array}{l}\text { Mean Body } \\
\text { Weight }(\mathrm{Kg}) \pm \mathrm{SD}\end{array}$ & \multicolumn{2}{|l|}{$59.0 \pm 7.28$} & \multicolumn{2}{|l|}{$58.74 \pm 8.10$} \\
\hline $\mathrm{T}$ value & \multicolumn{4}{|l|}{0.169} \\
\hline $\mathrm{P}$ value & \multicolumn{4}{|l|}{0.866} \\
\hline
\end{tabular}

NS: Not Significant 
The mean age in group I and L were 34.0 \pm 8.68 and 34.0 \pm 8.27 years respectively. There was no significant difference in the age of the patients between Group I and Group L $(\mathrm{p}=0.84)$. The mean body weight in Group I was $54.94 \pm 13.68$ kgs and in Group L it was $56.34 \pm 14.16 \mathrm{kgs}$. There was no significant difference in the body weight of patients between the Group I and Group L $(\mathrm{p}=0.544)$.

Table 2: Comparison of ease of insertion in between group I and group L

\begin{tabular}{|c|c|c|c|c|}
\hline \multirow{2}{*}{$\begin{array}{l}\text { Ease of } \\
\text { Insertion }\end{array}$} & \multicolumn{2}{|l|}{ Group I(i-gel) } & \multicolumn{2}{|c|}{ Group L(c-LMA) } \\
\hline & \begin{tabular}{|l|l}
$\begin{array}{l}\text { No. } \\
\text { patients }\end{array}$ & of \\
\end{tabular} & $\%$ & No. of patients & $\%$ \\
\hline Very Easy & 49 & 98 & 42 & 84 \\
\hline Easy & 0 & 0 & 3 & 6 \\
\hline Difficult & 1 & 2 & 5 & 10 \\
\hline Total & 50 & 100 & 50 & 100 \\
\hline pvalue & \multicolumn{4}{|l|}{$0.079(\mathrm{NS})$} \\
\hline \multicolumn{5}{|c|}{ Insertion Attempts } \\
\hline $1^{\text {st }}$ Attempt & 49 & 98 & 45 & 90 \\
\hline $2^{\text {nd }}$ Attempt & 1 & 2 & 5 & 10 \\
\hline Total & 50 & 100 & 50 & 100 \\
\hline
\end{tabular}

NS: Not Significant

The ease of insertion was not statistically significant between the two groups. $(\mathrm{p}=0.079) .49$ of $50(98 \%)$ insertions in group I were in the first attempt and only 1 patient required $2^{\text {nd }}$ attempt. 45

of $50(90 \%)$ in the group L required only one attempt and 5 patients required $2^{\text {nd }}$ attempt. In $2^{\text {nd }}$ attempt for insertion, airway manipulation with jaw thrust was required in both the groups.

Table 3: Mean duration for insertion and mean airway leak pressure:

\begin{tabular}{|l|l|l|}
\hline & $\begin{array}{l}\text { Mean duration of } \\
\text { insertion (secs) }\end{array}$ & Mean airway leak pressure $(\mathrm{cmH} 2 \mathrm{O})$ \\
\hline Group I & $17.26 \pm 2.93$ & $26.14 \pm 2.57$ \\
\hline Group L & $24.9 \pm 4.82$ & $19.76 \pm 2.04$ \\
\hline P value & $0.0001(\mathrm{HS})$ & $0.0001(\mathrm{HS})$ \\
\hline
\end{tabular}

HS: Highly Significant

The mean duration of insertion of i-gel in group I patients and c-LMA in group $\mathrm{L}$ patients was statistically highly significant. $(\mathrm{p}<0.001)$. The mean airway leak pressure with i-gel in group I patients was highly significant statistically $(\mathrm{p}<0.01)$ 


\section{JMSCR Vol||4||Issue||02||Page 9360-9370||February}

Figure 1: Intergroup comparison of mean heart rate (bpm)

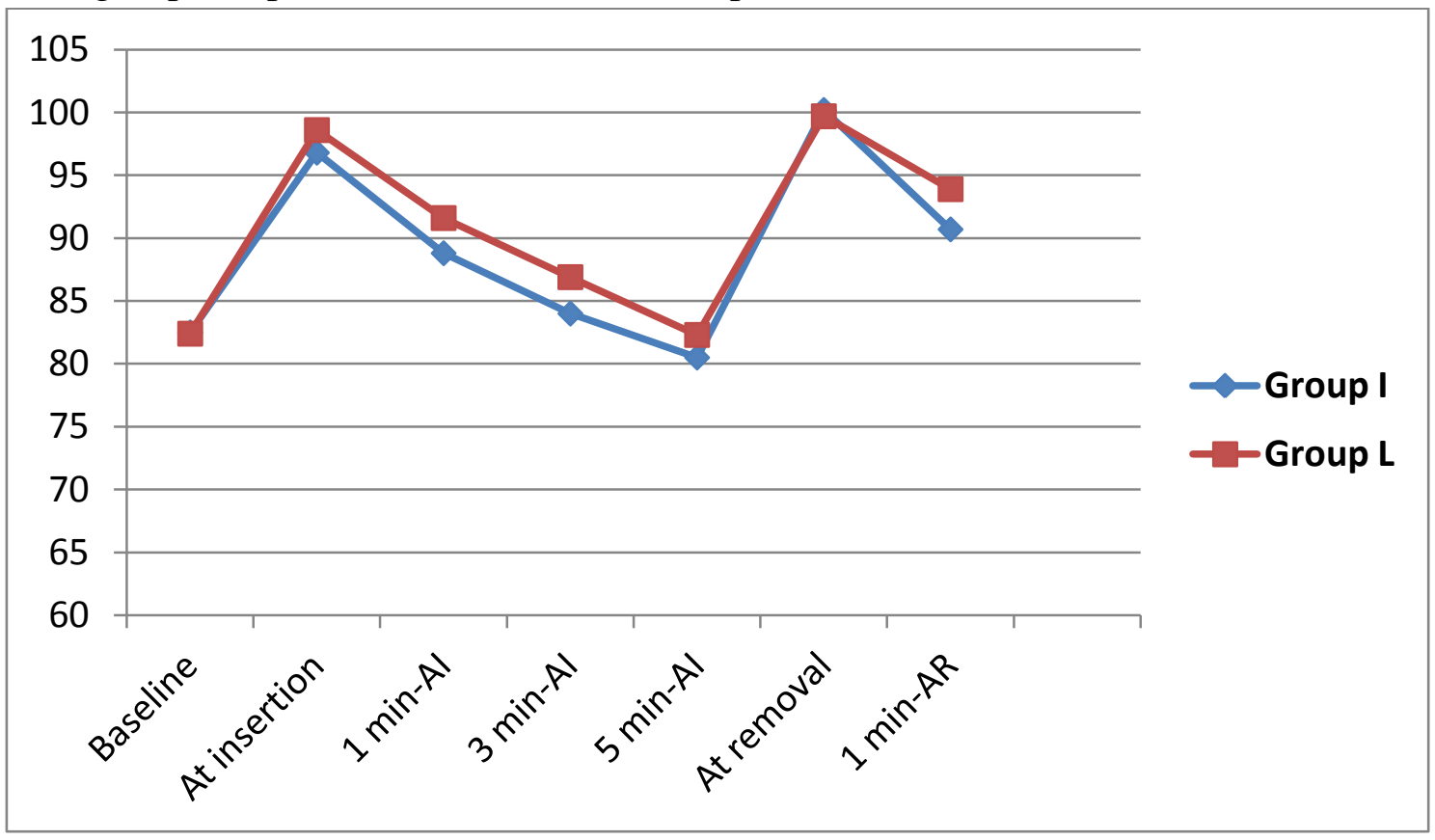

The basal heart rate was comparable in both groups $(\mathrm{p}=0.964)$. Statistical evaluation between the groups showed no significant difference in HR changes between group I and group L during the insertion of i-gel or c-LMA respectively and also after $1 \mathrm{~min}, 3 \mathrm{~min}$ and $5 \mathrm{~min}$ after insertion

Figure -2: Intergroup comparison of mean systolic blood pressure (mm of $\mathrm{Hg}$ )

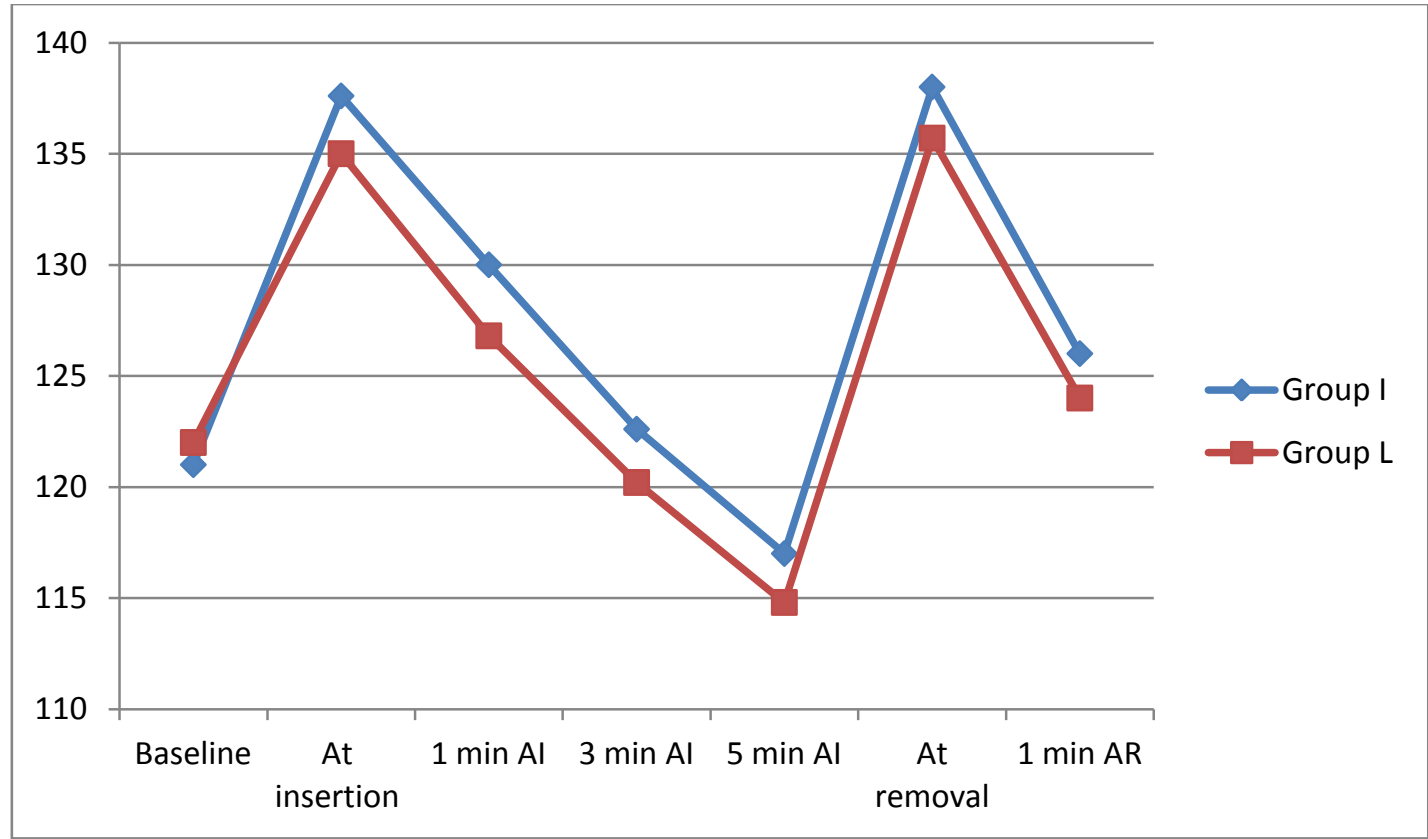

$(p<0.01)$ - Highly significant (HS); $(p<0.05)$ - Significant $(S) ;(p>0.05)$ - Not significant (NS); AI-After insertion; AR-After removal 


\section{JMSCR Vol||4||Issue||02||Page 9360-9370||February}

Figure-3: Intergroup comparison of mean diastolic blood pressure (mm of $\mathrm{Hg}$ )

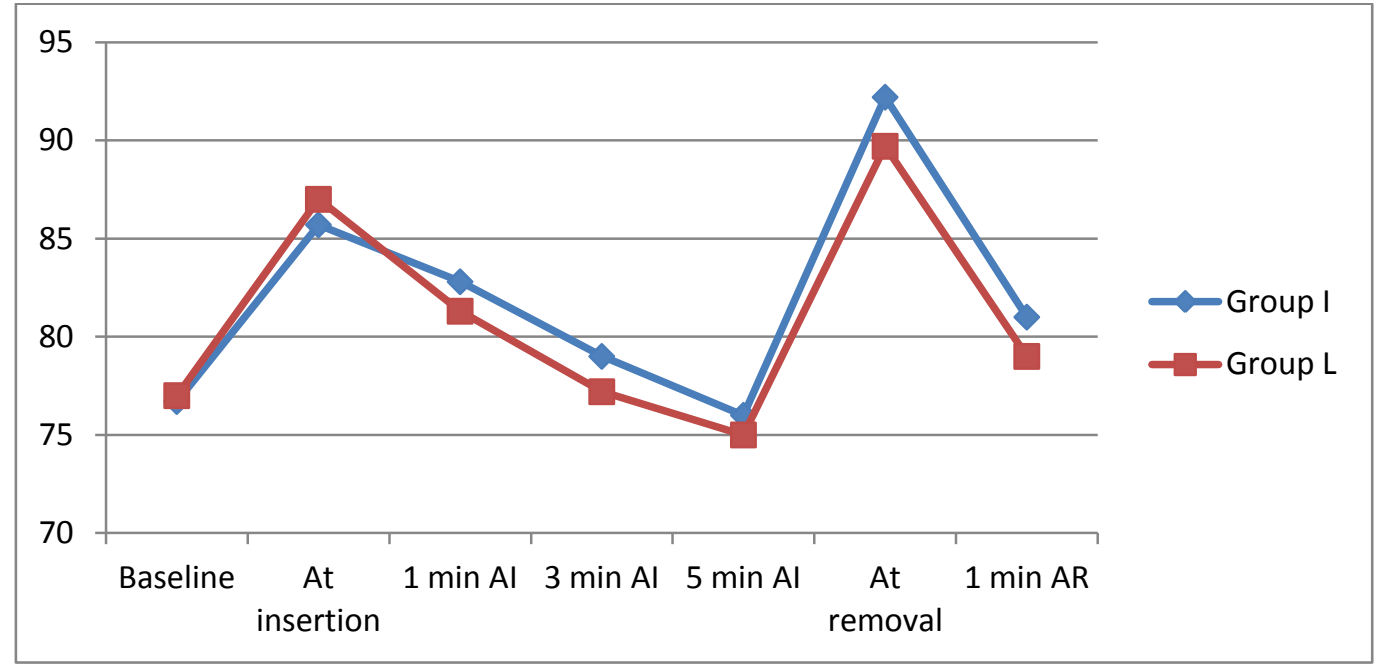

The mean basal DBP were comparable in both groups $(p=0.935)$. The mean DBP changes at the time of insertion of the device was not statistically significant. Statistical evaluation between the groups showed no significant difference in DBP changes between group I and group L during 1 $\min , 3 \mathrm{~min}$ and 5 mins after insertion. There was also no significant changes in DBP during removal and $1 \mathrm{~min}$ after removal of the devices between the groups.

Figure-4: Intergroup comparison of mean arterial blood pressure ( $\mathrm{mm}$ of $\mathrm{Hg}$ )

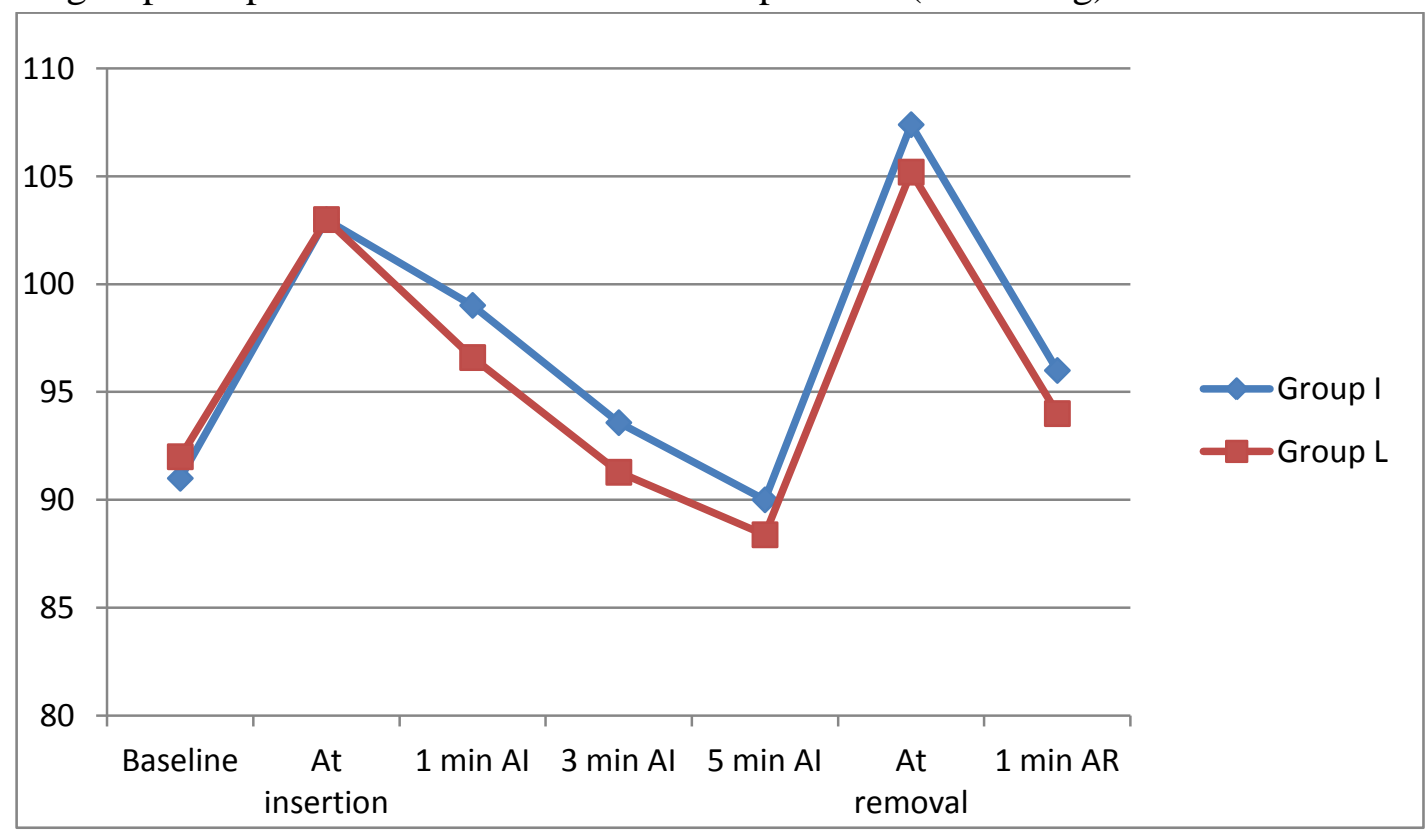

The mean basal MAP were comparable in both groups $(\mathrm{p}=0.795)$. Statistical evaluation between the groups showed no significant difference in MAP changes between group I and group L during the insertion of i-gel or c-LMA and also after $1 \mathrm{~min}, 3 \mathrm{~min}$ and $5 \mathrm{mins}$ of insertion. There was also no significant changes in MAP during removal and 1 min after removal of the devices in between the groups. 
Table 4: Showing the occurrence of post operative tongue/lip/tooth injury

\begin{tabular}{|l|l|l|l|l|l|}
\hline \multirow{2}{*}{$\begin{array}{l}\text { Post Operative } \\
\text { Complications }\end{array}$} & \multicolumn{2}{|l|}{\begin{tabular}{l} 
Group I(i-gel) \\
\cline { 2 - 6 } \\
patients of
\end{tabular}} & $\begin{array}{l}\text { Noup L(c-LMA) } \\
\text { patients of }\end{array}$ & $\%$ & P value \\
\hline $\begin{array}{l}\text { Tongue/Lip/to } \\
\text { oth injury }\end{array}$ & 3 & 6 & 5 & 10 & $0.461(\mathrm{NS})$ \\
\hline Sore Throat & 2 & 4 & 4 & 8 & 0.400 (NS) \\
\hline
\end{tabular}

NS-not significant

Lip injury was noted in 3 patients in group I (igel) out of 50 and in 5 patients out of 50 in group L(c-LMA). However the incidence was not statistically significant $(\mathrm{p}=0.461)$ when compared between both the groups. The incidence was not statistically different $(\mathrm{p}=0.400)$ when compared between the groups. The sore throat in all the 6 cases were mild requiring no treatment. None of the patients in both the groups developed post operative hoarseness or dysphagia.

\section{DISCUSSION}

The present prospective, randomized study was undertaken to compare two supraglottic airway devices i-gel and classic-LMA in anaesthetized and paralysed patients with respect to ease of insertion, number of attempts of insertion, airway leak pressure, haemodynamic changes and post operative complications.

Both the groups were comparable and there was no statistically significant difference with regards to mean age, weight, sex.

Ease of insertion: One of the primary objectives was to compare the ease of insertion between the two devices. The grading of insertion was done similar to the study conducted by Siddiqui et al., ${ }^{13}$ where insertion of device was recorded as; very easy (when assistant help was not required), easy (when jaw thrust was needed by assistant) and difficult (when jaw thrust and deep rotation or second attempt was used for proper device insertion).

There was no statistically significant difference between the two groups with respect to ease of insertion. ( $>>0.05)$. The insertion of i-gel was found comparatively easier and required less skill as compared to LMA but the results were not statistically significant. The i-gel having a non inflatable cuff and firm in consistency is much easier for insertion as compared to LMA. Our study compared the ease of insertion of the devices with the study conducted by Ali A et al., ${ }^{15}$ Siddiqui et al., ${ }^{13}$ Janakiram et al., ${ }^{16}$ who also did not find any statistically significant difference. Insertion of i-gel in our study was similar to Richez B et al., ${ }^{4}$ study, who graded insertion of igel as very easy in 93\% (66 of 71) patients and easy in remaining $7 \%$ (5 of 71) patients. Insertion of c-LMA in our study was comparable with Janakiram et al., ${ }^{16}$ study where $90 \%$ (45 of 50) cLMA insertions were easy insertions.

Number of attempts: In this study, insertion of igel was successful in first attempt in $98 \%$ patients as compared to $90 \%$ first time insertion with cLMA. Airway manipulation like jaw thrust was required during second attempt insertion in one patient of i-gel insertion and 5 patients with cLMA insertions. Very similar results were found in studies conducted by Helmy AM et al., ${ }^{2}$ Uppal $\mathrm{V}$ et al., ${ }^{10}$ Franksen $\mathrm{H}$ et al., ${ }^{11}$ Amini $\mathrm{S}$ et al., ${ }^{12}$ Siddiqui AS et al. ${ }^{13}$.In Janakiram et al., ${ }^{16}$ study, the success rate with first time i-gel insertion was only $54 \%$, and with c-LMA of $86 \%$ which was statistically highly significant. This was because, during the use of i-gel in 14 patients a larger size i-gel had to be used due to presence of audible leak and hence required $2^{\text {nd }}$ attempt. However, in our study we did not have such problem and hence the success rate of first time insertion was comparable between both the devices.

Time of insertion: The time for insertion was considered according to the study conducted by Helmy AM et al., ${ }^{2}$ from picking up the device to confirmation of effective ventilation by bilateral 
chest movement, square wave pattern capnography, normal range end tidal $\mathrm{CO}_{2}$ and stable arterial $\mathrm{SpO}_{2}(>95 \%) .{ }^{11,12}$ In our study, the time for insertion of i-gel (17.2s) was shorter compared to c-LMA (24.9s) which was highly significant statistically $(\mathrm{p}=0.0001)$.

The i-gel SAD is made of thermoplastic elastomer and has no cuff, hence requires less time for successful insertion as compared to c-LMA which has a cuff to be inflated after its insertion. Consistent with our results, Helmy AM et al., ${ }^{2}$ Uppal V et al., ${ }^{10}$ Parul $\mathrm{J}$ et al., ${ }^{9}$ also significant difference in the insertion times. In Franksen $\mathrm{H}$ et al., ${ }^{11}$ Amini $\mathrm{S}$ et al., ${ }^{12}$ Ali A et al., ${ }^{15}$ studies, though the mean time for i-gel insertion was clinically shorter as compared to c-LMA, it was not statistically significant.

Airway leak pressure: Airway leak pressure detection was performed in a similar manner done by Uppal $\mathrm{V}$ et al., ${ }^{10}$ in their study. The difference in the leak pressures between i-gel and c-LMA were statistically significant in our study $(\mathrm{p}=0.0001)$ similar to the previous studies of Janakiram et al., ${ }^{21}$ Franksen $\mathrm{H}$ et al., ${ }^{11}$ Amini $\mathrm{S}$ et al., ${ }^{12}$ and Helmy AM et al.,

Airway leak pressure of i-gel in our study was comparable with Uppal V et al., ${ }^{10}$ and Helmy AM et al., ${ }^{2}$ studies and of c-LMA with Amini $S$ et al., ${ }^{12}$ The efficacy of the oropharyngeal seal of the SAD depends on the fit between the structures surrounding the glottis and the distal mask of the SAD. With c-LMA, in order to obtain a good seal, the distal cuff has to be inflated. The i-gel made of thermoplastic elastomer is designed anatomically to fit the perilaryngeal and the hypopharyngeal structures without the use of an inflatable cuff. Its airway seal is likely to be higher than that of the LMA-Classic. ${ }^{15}$ This may be the reason for improved seal with the i-gel and hence higher airway leak pressures as compared with the cLMA.

Haemodynamic changes: During the insertion of LMA, pressor response (i.e. increase in heart rate and arterial pressure), may be induced by the passage of the LMA through the oral and pharyngeal spaces, pressure produced in the larynx and the pharynx by the inflated cuff and the dome of the LMA. ${ }^{9}$ During removal of LMA the hemodynamic response is probably triggered by pharyngeal stimulation during reverse rotation of the cuff. ${ }^{9}$ The same thing can also occur with insertion and removal of i-gel. The following haemodynamic parameters were recorded in all patients: Heart rate $[\mathrm{HR}]$ in beats per minute ,Systolic blood pressure [SBP] in $\mathrm{mm}$ of $\mathrm{Hg}$, Diastolic blood pressure [DBP] in $\mathrm{mm}$ of $\mathrm{Hg}$, Mean arterial pressure [MAP] in $\mathrm{mm}$ of $\mathrm{Hg}$. The above haemodynamic parameters were monitored in the following time interval - Basal before premedication, at the time of insertion, 1 minute after insertion, 3 minutes after insertion, 5 minutes after insertion, at the time of removal and 1 minute after removal. ${ }^{9}$ In our study, there was no statistically significant difference between i-gel and c-LMA with regard to heart rate, systolic, diastolic and mean blood pressure. The results of our study were similar to the studies done by Helmy AM et al., ${ }^{2}$ Franksen $\mathrm{H}$ et al., ${ }^{11}$ who in their studies found no significant difference between i-gel and c-LMA with regard to heart rate, arterial $\mathrm{BP}$.

Jindal $\mathrm{P}$ et al. ${ }^{9}$ in their study observed that i-gel produced less haemodynamic changes compared to other SADs. The authors concluded that i-gel effectively conforms to the perilaryngeal anatomy despite the lack of an inflatable cuff, it consistently achieves proper positioning for supraglottic ventilation and causes less hemodynamic changes as compared to other supraglottic airway devices like c-LMA which because of an inflatable cuff can produce more haemodynamic changes.

Injuries: The inflatable supraglottic airway devices, during insertion, the deflated leading edge of the mask can catch the epiglottis edge and cause it to down-fold or impede proper placement beneath the tongue and can cause pharyngeal injury. ${ }^{16}$ Inflatable masks also have the potential to cause tissue distortion, venous compression and nerve injury. ${ }^{16}$ 
In our study, the patients were inspected for any injury of the lips, teeth or tongue and the device for blood stain after its removal at the end of the surgery similar to study done by Siddiqui AS et al. ${ }^{13}$ Lip injury was noted in 3 patients in group I (i-gel) out of 50 and in 5 patients out of 50 in group L (c-LMA). However the incidence was not statistically significant ( $\mathrm{p}=0.461$ ). 2 cases in the $\mathrm{i}$ gel group had blood stain on the device on removal while there was no blood staining in any case of c-LMA group. Similar results have been observed in studies done by Helmy AM et al. ${ }^{2}$ In the study conducted by Siddiqui AS et al., ${ }^{13}$ blood on device was noted in 18\% patients of LMA group while none in the i-gel group which was statistically significant. The authors attributed the cause may be due to inflatable masks having the potential to cause tissue distortion, venous compression and nerve injury.

Post operative complications: 18-24 hours after surgery, patients were interviewed for any post operative complications like sore throat, dysphagia and hoarseness. Post operative sore throat graded as nil, mild, moderate and severe. $^{12,14} 2$ patients in group I had developed sore throat post operatively compared to 4 patients in group L. The incidence was not statistically different $(\mathrm{p}=0.400)$ when compared between the groups. The sore throat in all the 6 cases were mild requiring no treatment. None of the patients in both the groups developed post operative hoarseness or dysphagia. Our results were consistent with the studies done by Siddiqui AS et al., ${ }^{13}$

Helmy AM et al., ${ }^{2}$ Fanksen $\mathrm{H}$ et al., ${ }^{11}$ where the difference between LMA and i-gel regarding post operative complications was not statistically significant except nausea and vomiting which was significantly higher in LMA due to high incidence of gastric insufflation. ${ }^{2}$

Keijzer $\mathrm{C}$ et al., ${ }^{17}$ in their study compared the post operative throat and neck complications between LMA and i-gel. There was a higher incidence of sore throat and dysphagia at 1, 24, and 48 hours in the LMA group compared with the i-gel group.
Neck pain was also more common at 24 and 48 hours in the LMA group. Because of the absence of an inflatable cuff, the authors hypothesized that use of the i-gel produced fewer postoperative throat and neck complaints compared with a standard LMA.

\section{CONCLUSION}

Classic-LMA and i-gel can be used safely and effectively during general anaesthesia with positive pressure ventilation in selected patients. Both devices are easy to insert. The i-gel provides a better airway sealing pressure compared to cLMA. The i-gel has low pharyngolaryngeal morbidity rate as compared to c-LMA.

\section{REFERENCES}

1. Pennant JH, White PF. The laryngeal mask airway: Its uses in anaesthesiology. Anaesthesiology 1993;79:144-163.

2. Helmy AM, Atef HM, El-Taher EM, Henidak AM. Comparative study between i-gel, a new supraglottic airway device, and classical laryngeal mask airway in anesthetized spontaneously ventilated patients, Saudi J Anaesth 2010;4(3):131-6.

3. Dorsch JA, Dorsch SE. Understanding Anesthesia Equipment.

4. Richez B, Saltelf L, Banchereaur, Torrielli, Cros AM. A New Single Use Supraglottic Airway Device with a Noninflatable Cuff and an Esophageal Vent: An Observational Study of the i-gel. Anesth Analg 2008;106(4):1137-9.

5. Kannaujia A, Srivastava U, Saraswat N, Mishra A, Kumar A, Saxena S. A Preliminary Study of i-gel:A New Supraglottic Airway. Indian Journal of Anaesthesia 2009;53(1):52-6.

6. Brimacombe J. The advantages of LMA over the tracheal tube or face mask: a meta-analysis. Can J Anaesth 1995;42(11) :1017-23.

7. Keller C, Brimacombe J, Bittersohl J, Lirk P, Goedecke A. Aspiration and the 
laryngeal mask airway: three cases and a review of the literature, British Journal of Anaesthesia 2004;93(4):579-82.

8. Schmidbauer W, Bercker S, Volk T, Bogusch G, Mager G, Kerner T. Oesophageal seal of the novel supralaryngeal airway device i-gel TM in comparison with the laryngeal mask airways Classic and ProSeal using a cadaver model. British Journal of Anaesthesia 2009;102(1):135-9.

9. Jindal P, Rizvi A, Sharma JP. Is i-gel a new revolution among supraglottic airway devices? A comparative evaluation. MEJ Anesth 2009;20(1):53-8.

10. Uppal V, Gangaiah S, Fletcher G, Kingsella J. Randomized crossover comparison between the i-gel and the LMA-Unique in anaesthetized, paralysed adults. Br J Anaesth 2009;103(6):882-5.

11. Franksen H, Renner J, Hanss R, Scholz J, Doerges V, Bein B. A comparison of the igel $^{\mathrm{TM}}$ with the LMA-Unique in nonparalysed anaesthetised adult patients. Anaesthesia 2009;64:1118-24.

12. Amini S, Khoshfetrat M. Comparison of the Intersurgical Solus laryngeal mask airway and the i-gel supralaryngeal device. Anaesthesia 2010;65(8):805-9.

13. Siddiqui AS, Raees US,Siddiqui SZ, Haider S, Raza SA. Comparison of performance and safety of i-gel with laryngeal mask airway (classic) for general anaesthesia with controlled ventilation. Anaesth, Pain and Intensive Care 2010;14(1):17-20.

14. Uppal V, Fletcher G, Kinsella J. Comparison of the i-gel with the cuffed tracheal tube during pressure-controlled ventilation. British Journal of Anaesthesia 2009;102:264-8.

15. F Ali A, Ali L, Sheikh NA, Siddique SA. Airway device: comparison of i-gel supraglottic with laryngeal mask airway. Professional Med J 2010 Dec;17(4):643-7.

16. Janakiraman C, Chethan DB, Wilkes AR, Stacey MR, Goodwin N. A randomised crossover trial comparing the i-gel supraglottic airway and classic laryngeal mask airway. Anaesthesia 2009;64:674-8.

17. Keijzer C, Buitelaar DR, Efthymiou KM, Sramek M, Cate J, Ronday M, et al. A Comparison of postoperative throat and neck complaints after the use of the i-gel and the La Premiere disposable laryngeal mask: A double blinded, randomized, controlled trial. Anaesthesia and Analgesia 2009;109(4):1092-5. 